\title{
Formation of the perspective innovation policy of the enterprise in the conditions of organizational-economic changes
}

\author{
Svetlana Uvarova ${ }^{1, *}$, Vyacheslav Vlasenko ${ }^{1}$, Anatoly Bukreev², Ludmila Myshovskaya ${ }^{1}$, \\ Olga Kuzina ${ }^{3}$ \\ ${ }^{1}$ Voronezh State Technical University, Moscow Avenue, 14, Voronezh, 394026, Russia \\ ${ }^{2}$ Department of Economic development of Voronezh region, Lenin Square 1, Voronezh, 394018, Russia \\ ${ }^{3}$ Moscow State University of Civil Engineering, Yaroslavskoye shosse 26, Moscow, 129337, Russia
}

\begin{abstract}
This article is based on the analysis of modern condition and dynamics of innovational development of high-rise buildings construction. A number of cardinal organizational and economic changes in management at the macro and meso-levels is taken into the account. Principal scheme of development of the methodology of formation of perspective innovation politics in high-ruse buildings construction based on inculcation of modern methods of strategic control of innovational activity is suggested in this article.
\end{abstract}

\section{Introduction}

The radical reorganization of the economic management system associated with the transition to self-regulation and innovative development is one of the most important, - one of the most important directions of reforms carried out in our country [1]. This problem is of particular importance at the level of the construction organization, whose position in the market economy is radically changing.

The The process of building production is formed under the influence of a large number of organizational factors. Transformation of the management system and its improvement means, first of all, a change in organizational relations and, accordingly, organizational forms of management.

Often, these changes lead to the reorganization and restructuring of enterprises, to the search for new network interactions that are more or less effective than already existing ones. The effectiveness of organizational changes in the activities of the construction organization is correlated with the conditions of the external environment, fluctuations in the economic cycles of business activity, realized and spontaneous organizational and economic changes, communication system of the enterprise [2].

From this point, the study of the specifics of both strategy and formation of perspective innovational politics of construction organization in modern economy in Russia is an urgent research topic that requires a serious scientific approach. The development of the problem of

*Corresponding author: uvarova_s.s@mail.ru 
the creation of the strategy of the effective management and the formation of perspective innovation politics of the development of the construction organization considering cyclicality of economic development, already realized and also planned changes (organized, as well as institutional) on managements macro level, basing on the realization of the potential of the development and innovational infrastructure institutes, due to the improvement of regional investment and construction complexes in the regions is a relatively new scientific direction.

\section{Materials and Methods}

Effective economical politics in innovation activity of construction companies management should be dedicated not only to maintain positive development trends for the development of the investment and construction complex, but to remove restrictions that prevent their continuation [3].

First trend is to form the "raw-innovation" contour. Since innovations relate, first of all, to resource saving [4], a market is formed for innovations in the investment and construction complex, namely, in the building materials industry. The logically arising task of modernization of transport and energy infrastructure is also connected with the construction industry. Thus, the general economic trend of the innovative development of the commodity sector is transformed into a development trend of the investment and construction complex, which consists in the formation of the need for innovative development of construction technology and technology for resource conservation.

Second important trend is the formation of a high-quality consumer market. This is due to the sociological trend of forming a "new middle class". The trend that has arisen in the service market has spread to the housing construction sector, and subsequently to the commercial real estate market, which reflects the idea of creating a new quality human environment [5].

Thus, it is necessary to have management, which will provide resonant effect on systems elements to develop trends further, which is the first imperative condition for achieving innovative development of the investment and construction complex.

However, as the research results and their own analytical calculations of the authors show, there are a number of restrictions for further innovation for sustainable economic development, including investment and construction complex. The nature of the emergence of restrictions can be either spontaneous (spontaneous organizational and economic, institutional, technical and technological, natural changes in both the external and internal environment can lead to the formation of constraints), and initiated (initiated changes made without assessing the consequences, incorrect methods, or without agreement with the system's own movements can also lead to the formation of restrictions). The effect of restrictions can lead the system of investment and construction complex to the choice of an unstable development trajectory, or to a change in the region of attraction of the chosen attractor, which leads to a change in the "goals" of the system, and, ultimately, to the choice of an unstable development trajectory [6].

To overcome the limitations and ensure a qualitatively new development of the investment and construction complex, it is necessary to qualitatively change the regulatory role of the state associated with the necessary adjustment of the market mechanism and its regulators, based on coordination of the activities of state institutions and public structures, their de-bureaucratization, and the development of a national development trend. Realization of tasks which are necessary to achieve innovative development must be accompanied by certain managerial decisions of power structures and actions that must be taken ahead of time in conditions of risk and uncertainty [7]. Therefore, the state management of the investment and construction complex should be based on the analysis of worldwide and Russian 
development trends, public and business community views, on the presentation of future forms of organization of inter-industry interactions, especially in connection with the processes of globalization.

The public administration of the investment and construction complex should take into account the already accomplished spontaneous and initiated changes.

Accordingly, there is a need to develop conceptual and methodological foundations for the strategy and perspective innovative policy of construction enterprises, taking into account changes, as well as planning the reforms that have already been taken to ensure their systemic and successful implementation, which is appropriate for a program-targeted approach.

The mechanism and methodological basis for the implementation of the innovation strategy is the innovation process and its innovative projects. The methodological basis of the innovation strategy (based on the thesis on the two-level nature of the concept of strategy) is the concept of the overall management of the enterprise and its functional subsystems.

Thus, innovational strategy is a conception of interaction between company and external environment, based on the methodology of anticipating the implementation of technological, organizational, economic changes (representing a portfolio of innovative projects that implement the innovation process) with the aim of adapting the internal environment and shaping market development trends in the form of sustainable competitive advantages.

Proceeding from the foregoing, an objective need arises to justify a new concept for the formation of a promising innovation policy and the development of a strategy of a construction organization, allowing to significantly improve its investment and construction activities by stimulating innovative processes, introducing modern methods of strategic management of regional zoning and creating "points of innovation growth" that take into account the institutional, economic, organizational, information, analytical and regional aspects of governance.

Proceeding from the complexity and multidimensionality of the positioned problemp, there is a need to solve a number of interrelated but quite diverse tasks from the point of view of both their hierarchy (macro-, meso- and microlevel) and the direction (institutional, organizational, economic, regional aspect), as well as the methodology used (econometric methods, methods the theory of graphs, the methodology of territorial zoning, etc.). In general, a basic scheme for the development of a methodology for the formation of a promising innovation policy in construction on the basis of the introduction of modern methods of strategic management of innovation activity is presented in Figure 1.

At the first stage, in order to determine the current state (initial coordinates) and problems of innovation development of construction organizations, as well as the structure of construction management, taking into account the implemented transformations, we consider it necessary to assess the statics and dynamics of innovation in construction, to analyze the impact on its dynamics and the effectiveness of state and regional policy [8]; to assess the effectiveness of the functioning of development institutions and the correlation with the results of the activity of construction enterprises; to carry out the analysis of innovation strategies of large construction enterprises; to determine the specifics of innovation activity of large, medium and small enterprises; assess the dependence of innovative activity of enterprises on the pricing and audit of investment and construction projects; to formulate the target blocks of problems and the factor space of innovation in construction. 


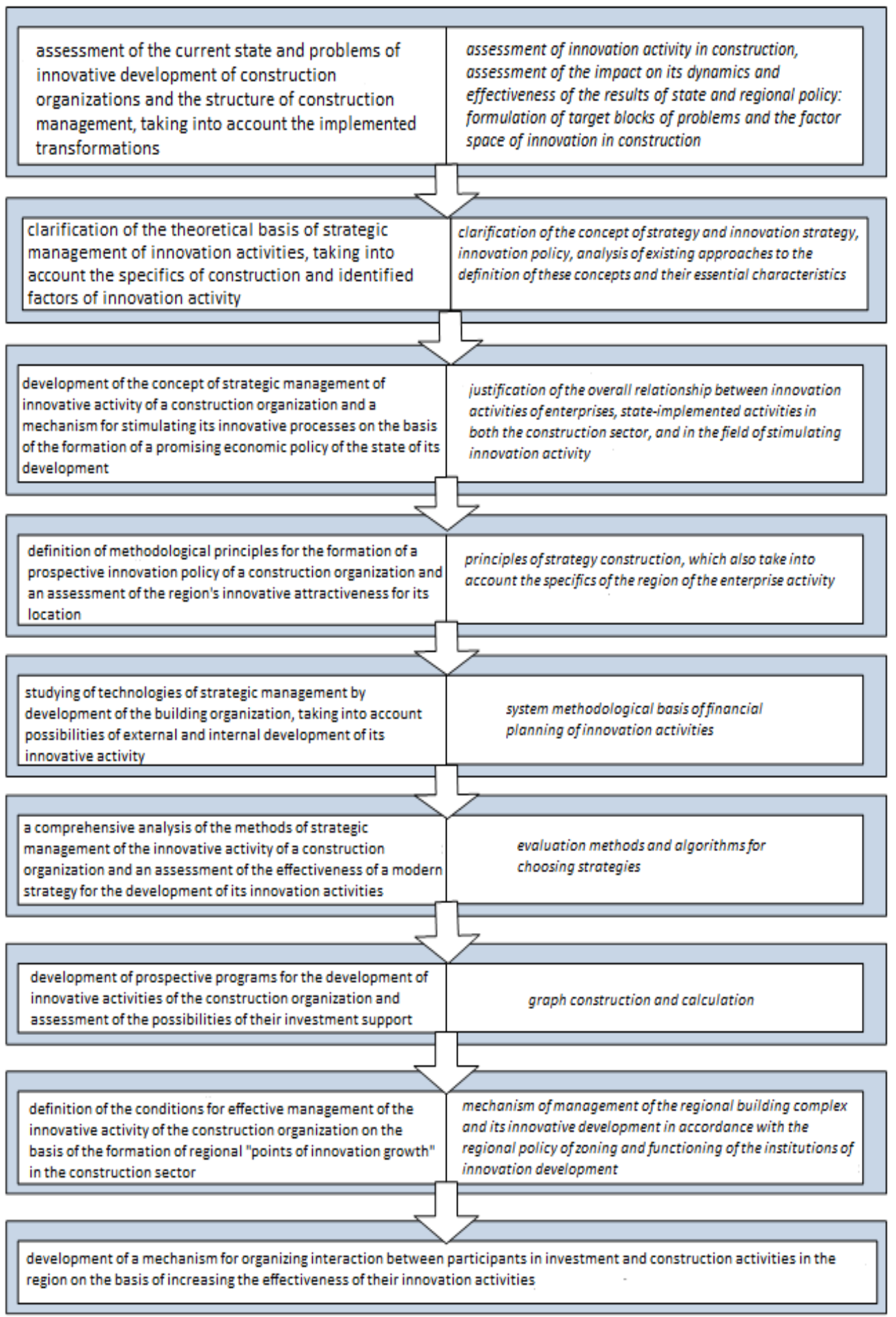

Fig. 1. Principal scheme for the development of a methodology for the formation of a promising innovation policy in construction on the basis of the introduction of modern methods of strategic management of innovation activities 
Further, in order to unify the conceptual apparatus and to increase the effectiveness and coherence of institutional transformations, it is necessary to clarify the theoretical basis for the strategic management of innovation activities, taking into account the specifics of construction and identified factors of innovation activity. Within the framework of the solution of this complex of problems, we analyzed the concept of an innovation strategy, defined significant features of the concept, which will be sent methodological principles, as well as methodological tools developed for a large construction enterprise.

On the basis of the concept, the principles for building a strategy are formulated, which also take into account the specific nature of the region of the enterprise's activity (in this aspect, we consider it necessary to take into account, among other things, the specific state zoning policy at the regional level).

Further, within the framework of a comprehensive analysis of the methods of strategic management of the innovative activity of the construction organization and evaluation of the effectiveness of the modern strategy for the development of its innovative activity, we developed evaluation methods and algorithms for selecting optimal strategies. When forming a strategy, a sustainable development of an enterprise is a prerequisite, in which it develops at any stage of the business cycle, returning to the trajectory of its development after the crisis.

The most important stage in the development of the methodology for the formation of a promising innovation policy is to determine the conditions for effective management of the innovative activity of the construction organization on the basis of the formation of regional "points of innovation growth" in the construction sector. The mechanism of management of the regional construction complex and its innovative development should be formed in accordance with the regional policy of zoning and functioning of innovation development institutions: it is construction that should give impetus to innovative development, uniting enterprises of various industries in the operation of technoparks and special economic zones, development of the infrastructure of the city and the region.

\section{Results}

As a result, when implementing the proposed recommendations, especially at the meso-level of management, we consider it necessary to make an assessment of the quality of management at each stage of the life cycle when planning and implementing the initiated changes in the formation of a promising innovation policy.

It is worth noting the difference in the understanding and criteria for assessing the quality of management, depending on the purpose of the assessment, the scale of the problem and the policy being implemented, but ultimately the quality of public administration manifests itself in its impact on the socio-economic development of the country, region, complex, industry. In general, the following scheme for assessing the quality of public administration can be cited (Figure 2).

Management cost should provide not only actual reduce of administrative expenses for companies and regional investment and construction complex, but also reduction initial wastes on regulation which can be provided by continuity of institutional changes.

When determining the public administration effect on each type of measures, it is necessary to take into account the prospects for the development of technologies and methods that ensure the economy of natural resources, environmental safety of production activities, improve the level and quality of life of the population, modernize the country's production base, preserve and grow the competitiveness of the enterprise under WTO conditions. 


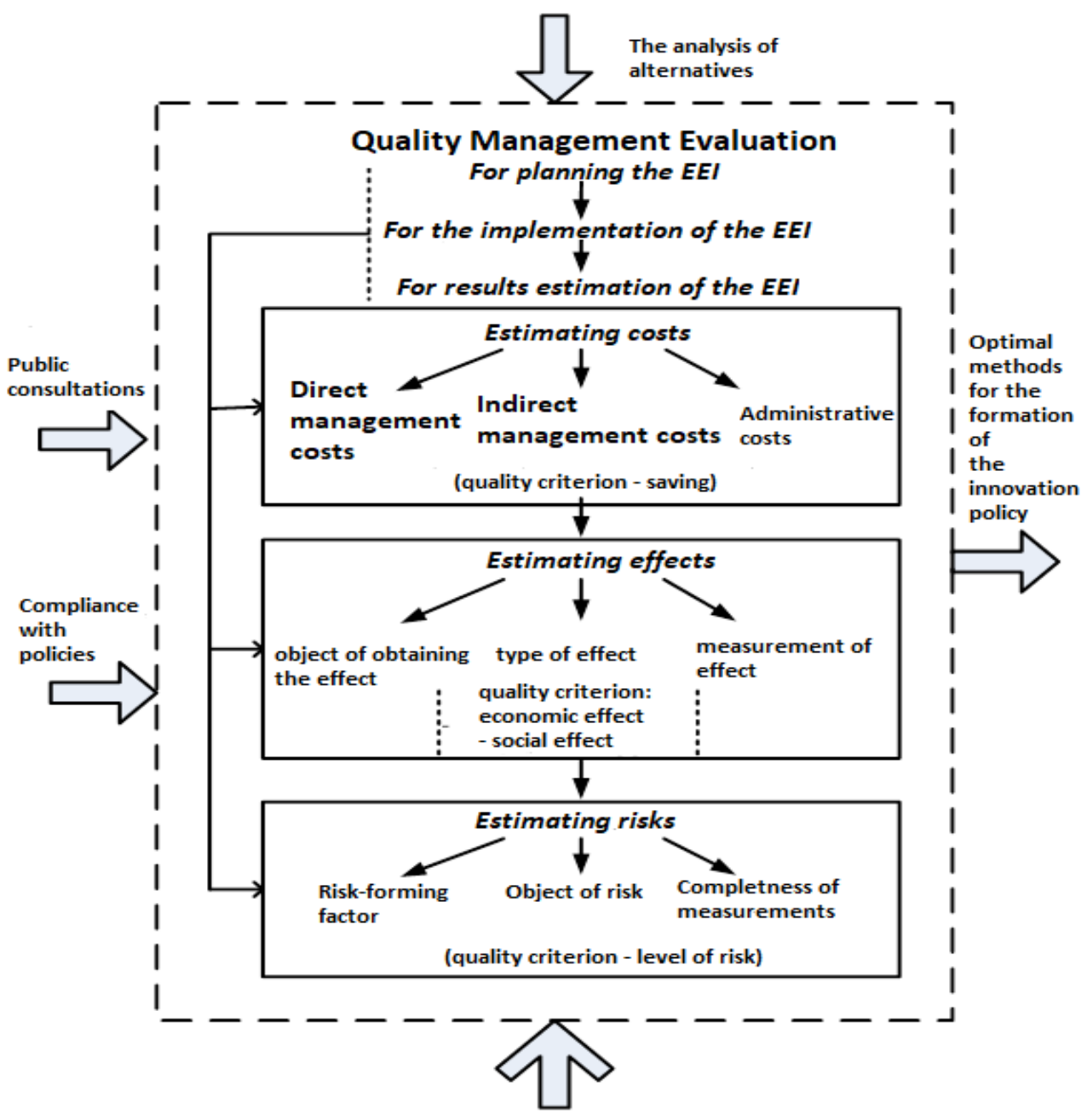

\section{Functions of state regulation of ISK}

Fig. 2. Management quality assessment scheme

Reducing the risk degree of management of an enterprise or a regional investment and construction complex implies the need to take into account the already accomplished spontaneous and initiated changes, which ensures the implementation of the principles of optimality and complexity. In addition, when planning the formation of innovative policy, it is necessary to build on the analysis of global and Russian development trends, the views of the public and the business community, on the presentation of future forms of organization of inter-industry interactions, especially in connection with the processes of globalization

\section{Discussions}

It should be noted that innovations (including technological ones) are often a source or a catalyst of organizational and economic changes.

Analyzing the scientific approaches to the content of the notion of innovation, it is possible to identify a number of authors, that distinguish an essential feature of innovation as a change (replacing the old with a new one). Thus, innovations can be interpreted as changes, therefore, applying the methodology of planning and implementing organizational and 
economic changes to the planning and implementation of innovations, it can be concluded that innovation is constantly introduced by all elements of the managed subsystem of the investment and construction complex. In addition, in the previous paragraphs of the study it is shown that each element of the managed subsystem of the investment and construction complex is in the process of constant updating on the basis of economic changes characterized by signs of innovation (the production and economic subsystem), institutional changes (institutional subsystem), organizational changes (social subsystem), which has the character of self-development. Self-development is caused by the tendency to self-regulation and constant learning in the social subsystem, by the formation of legislative initiatives by the business community in the institutional subsystem, by the search for financing mechanisms and by the interaction in the implementation of projects in the production and economic subsystem. The aspiration of all the classification elements of a managed subsystem to continuous improvement and renewal is their integrative characteristic. In accordance with the integrative characteristic, the principle of innovation is put forward: technical and technological innovations are one of the main driving forces and reasons for organizational and economic changes (organizational innovations).

This thesis confirms and justifies the necessity and timeliness of developing the methodology and methodological foundations for the formation of a promising innovation policy in the context of the already implemented and planned organizational and economic changes in the management system of the investment and construction complex.

\section{Conclusion}

The proposed methodological foundations can be used to improve the mechanisms of strategic management and effective development of innovative activities of the construction organization in the modern economy of Russia, as well as to increase the efficiency of the regional investment and construction complex by building a promising innovation policy in accordance with the implemented organizational and economic changes.

\section{References}

1. A. Zehavi, D. Breznitz. Distribution sensitive innovation policies: Conceptualization and empirical examples. Research Policy, Volume 46(1), p. 327-336 (2017)

2. K.M. Gumba, M.I. Mamaev, Conceptual foundations for the formation of sustainable competitive advantages. News of the Irkutsk State Economic Academy (Baikal State University of Economics and Law). 1. pp 11 (2014)

3. K.M. Gumba, S.V. Rodionova Substantiation of the essence and effectiveness of managerial innovations in the enterprise. Economics and Entrepreneurship. 11-3 (52-3). P. 645-647 (2014)

4. K.M. Gumba, S. Belyaeva IOP Conference Series: Earth and Environmental Science 90. 012163. (2017)

$\begin{array}{lllll}\text { 5. V. Kankhva } & \text { Procedia } & \text { Engineering } & 165 & \text { 1300-1304. }\end{array}$ (2016) doi:10.1016/j.proeng.2016.11.855

6. V.S. Kankhva, S.S. Uvarova, S.V. Belyaeva Procedia Engineering. 165. p. 1046-1051. (2016)

7. L. Grilli, M. Mazzucato, M.e Meoli, G. Scellato. Technological Forecasting and Social Change, 127, Pages 1-7, (2018)

8. E. Nezhnikova IOP Conf. Series: Earth and Environmental Science 90 (2017) 012162. doi :10.1088/1755-1315/90/1/012162 